\title{
A Uerj e o Futuro do Rio de Janeiro
}

\section{Nota dos Editores}

\section{(2) OpenEdition \\ Journals}

Electronic version

URL: http://journals.openedition.org/espacoeconomia/2561

DOI: 10.4000/espacoeconomia.2561

ISSN: 2317-7837

\section{Publisher}

Núcleo de Pesquisa Espaço \& Economia

\section{Electronic reference}

Nota dos Editores, «A Uerj e o Futuro do Rio de Janeiro », Espaço e Economia [Online], 9 | 2016, Online since 17 January 2017, connection on 24 September 2020. URL : http://journals.openedition.org/ espacoeconomia/2561; DOI : https://doi.org/10.4000/espacoeconomia.2561

This text was automatically generated on 24 September 2020.

(C) NUPEE 


\section{A Uerj e o Futuro do Rio de Janeiro}

\section{Nota dos Editores}

1 Publicamos nesta edição a carta aberta publicada pelo Magnífico Reitor, Prof. Dr. Ruy Garcia Marques, e pela Vice-Reitora, Prof. ${ }^{a}$ Dr.. Maria Georgina Muniz Washington, da Universidade do Estado do Rio de Janeiro (UERJ), Rio de Janeiro, Brasil. Trata-se de um manifesto em defesa da Universidade, que está sendo vergonhosamente destruída pelo Governo do Estado do Rio de Janeiro, com o olhar complacente da administração federal.

2 Espaço e Economia: Revista Brasileira de Geografia Econômica foi criada dentro da UERJ, no âmbito do Grupo de Pesquisa Espaço e Economia (NUPEE). Queremos somar nossos esforços ao de toda a comunidade da UERJ e a toda comunidade científica do Brasil e do Mundo que lutam contra mais esse retrocesso na educação e na produção científica brasileira.

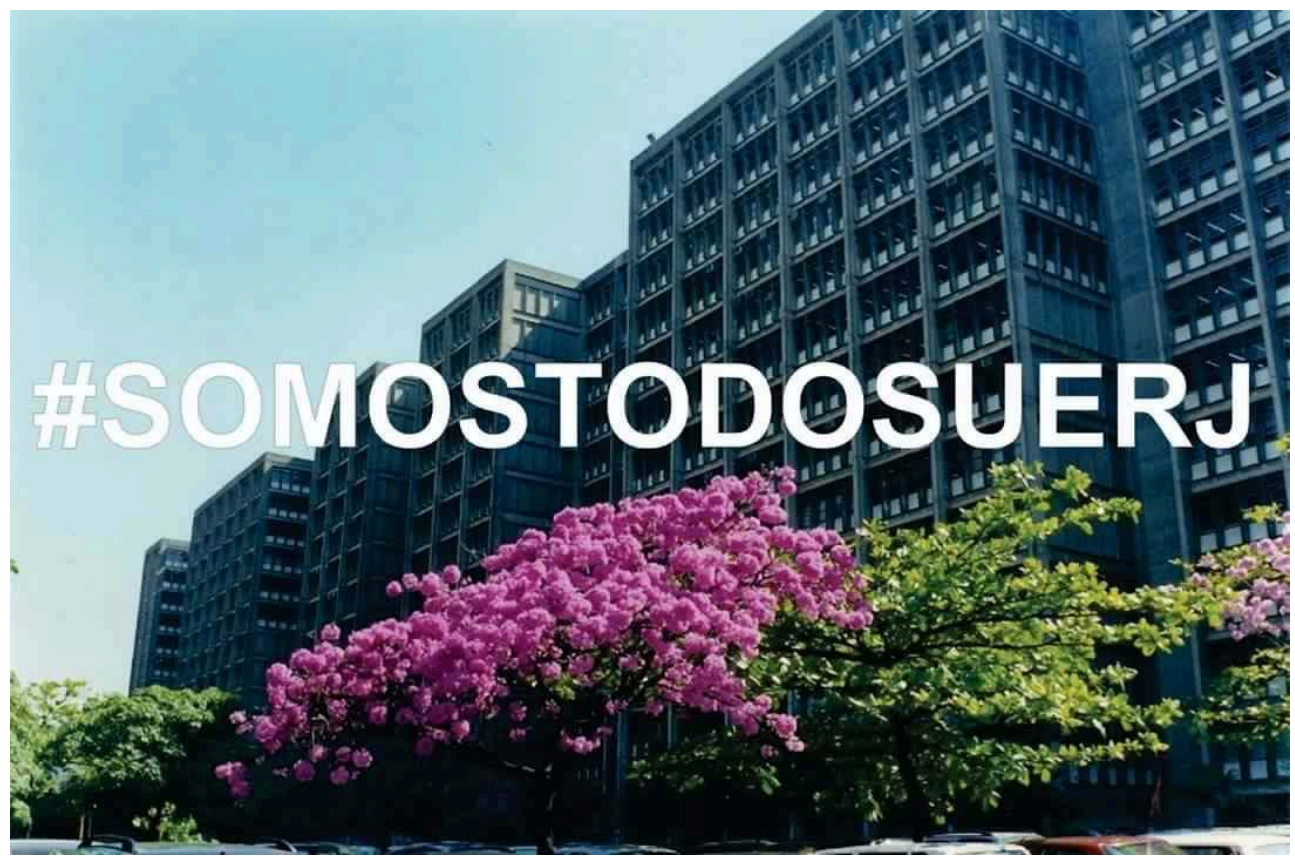




\section{A Uerj e o Futuro do Rio de Janeiro}

3 A Universidade do Estado do Rio de Janeiro (Uerj), ao longo das suas mais de seis décadas de existência, cresceu e firmou-se como uma das principais universidades do País. Atualmente, é a $11^{a}$ colocada em qualidade entre as 195 universidades brasileiras, segundo o ranking da Times Higher Education de 2016, e a $20^{\mathrm{a}}$ entre todas as universidades da América Latina.

4 Quando se considera o item "inserção de seus alunos no mercado de trabalho", a Uerj ocupa o $8^{\circ}$ lugar e, no item "produção científica", ela é a 9", segundo o ranking das universidades brasileiras da Folha de São Paulo.

5 São cerca de 35 mil alunos em seus cursos de graduação, nas modalidades presencial e de ensino a distância, mais de 4 mil em cursos de mestrado e doutorado, cerca de 2 mil em cursos de especialização e 1,1 mil nos ensinos fundamental e médio (Instituto de Aplicação - CAp-Uerj). Além do Campus Maracanã, dispõe-se em 13 unidades externas, constituindo seis campi regionais espalhados pelo Estado do Rio de Janeiro, colaborando com seu desenvolvimento regional.

6 São também da Uerj unidades de saúde, como o Hospital Universitário Pedro Ernesto (HUPE), a Policlínica Piquet Carneiro (PPC) e a Universidade Aberta da Terceira Idade (UnATI), esta última um importante projeto de extensão, com várias premiações internacionais.

7 O HUPE é um dos maiores e melhores hospitais do Rio, com mais de 500 leitos, 10.000 internações/ano e mais de 180.000 consultas ambulatoriais especializadas/ano. A PPC é responsável por mais de 200.000 consultas/ano e cerca de 8.000 cirurgias ambulatoriais/ano.

8 Fica clara, portanto, a importância da Uerj no cenário educacional de nosso Estado, bem como seu impacto positivo para a nossa economia, preparando recursos humanos muito qualificados para as áreas da indústria, da tecnologia, do comércio, da educação, da saúde e da pesquisa avançada. Um sem-número de nossos alunos tornam-se inovadores e empreendedores, gerando empregos e riquezas para o Rio de Janeiro.

9 Todos sabemos que a criação de novas indústrias no Rio de Janeiro é um ambicioso projeto de nossos governantes. Como elas poderão se instalar e continuar a oferecer empregos, sem a geração da mão de obra necessária? Como produzirão renda, sem a capacidade instalada laboratorial necessária para gerar inovação? Como produziremos riqueza, sem o conhecimento?

10 Não há progresso sem educação! São senhores do tempo aqueles que elegem a educação como prioridade, ninguém mais duvida disso.

11 Foram tempos difíceis aqueles em que a educação não era considerada um direito. Árduos tempos em que se tenta a efetivação do direito à educação em todos os níveis.

12 Há anos, um enorme esforço tem sido exigido por nossa sociedade nesse sentido. 0 esforço de um batalhão de operários da educação, em todos os níveis, tem sido recompensado por instituições educacionais mais pujantes para abraçar os ideais de uma sociedade justa e fraterna.

13 Entretanto, a Uerj está sendo sucateada, numa absoluta falta de visão estratégica por parte dos governantes do nosso Estado, a quem incumbe o financiamento de uma universidade pública e inclusiva como a nossa. 
14 Desprezar o ensino superior, a pós-graduação e a pesquisa é apostar na miséria, na violência e num futuro sem perspectivas positivas.

Forçar o fechamento da Uerj é não pensar no futuro de nosso estado e de nosso país.

15 A Uerj e o Estado são perenes, os governantes não.

16 Ruy Garcia Marques - Reitor

17 Maria Georgina Muniz Washington - Vice-reitora

18 Com o apoio de ex-reitores da Uerj: Ivo Barbieri, Hésio Cordeiro, Antonio Celso Alves Pereira, Nilcea Freire, Nival Nunes de Almeida, Ricardo Vieiralves de Castro 